\title{
EFFECT OF PULSE PARAMETERS ON SURFACE FUSION OF STEEL BY TUNGSTEN INERT GAS PULSED ARCING
}

\author{
Somnath Basu ${ }^{1}$, P.K.Ghosh ${ }^{2}$, J.S.Saini ${ }^{3}$ \\ ${ }^{1}$ Research Scholar, Mechanical Engineering, Uttarakhand Technical University, Dehradun, India \\ ${ }^{2}$ Professor, MMED, IIT, Roorkee, India \\ ${ }^{3}$ Professor, ME, DIT University, Dehradun, India
}

\begin{abstract}
Tungsten inert gas pulse arcing (TIGPA) has been employed at various arcing parameters keeping the net heat energy input constant for surface fusion of Martensitic stainless steel(SS-410) and High Carbon alloy steel(En-31). The process has ability to control the energy input and its distribution which significantly influences the melting and solidification behavior of base material. At different arcing parameters surfaces were fused. .Fused zone width and depth were measured. Ripples formed on fused surface were studied and their dimensions were measured to estimate cooling rates.Hardness of surface across arc travel direction were measured .A dimensionless parameter was used to find its relationship with all the measured and estimated data .
\end{abstract}

Keywords: TIG Pulse Arcing, Stainless Steel, High Carbon Steel, Fusion Zone

\section{INTRODUCTION}

Pulse current has unique ability to control energy input as well as its distribution. So it is preferred over conventional constant current welding processes in many applications. Pulse processes can operate at a relatively higher energy input during peak current but maintains a relatively low net heating of the base material (BM) primarily due to interruption in arcing. So BM is subjected to interrupted fusion and solidification. It allows greater control of heating with comparatively larger fusion zone (FZ) width and deeper penetration. Advantages of pulsing over conventional MIG welding of Al-Mg alloy has already been studied. [i]. Tungsten inert gas pulse welding process uses non consumable electrode. So autogenous fusion of material can be achieved by arcing through this method. The effect of Tungsten inert gas pulse arcing (TIGPA) has been studied on micro alloyed HSLA. [ii].

The control of pulse current process is quite complicated due to involvement of its simultaneously interacting parameters like peak current $\left(\mathrm{I}_{\mathrm{P}}\right)$, base current $\left(\mathrm{I}_{\mathrm{b}}\right)$, pulse frequency (f), peak current duration $\left(t_{p}\right)$ and base current duration $\left(t_{b}\right)$. This problem has been solved by using a hypothetically derived dimensionless factor $\phi$ in MIG and TIG arcing processes [i, ii]. The dimension less parameter is expressed as equation (1):

$$
\phi=\left(\left(\mathrm{I}_{\mathrm{b}} / \mathrm{I}_{\mathrm{P}}\right) \mathrm{ft}_{\mathrm{b}}\right.
$$

In this work effort has been made to study the effect of $\phi$ on fusion of SS-410 and En-31 steel. Surface ripples which are indicative of cooling pattern, depth and width of FZ have been measured and a correlation with $\phi$ has been discussed. Change in hardness has also been measured.

\section{EXPERIMENTAL WORK}

Studies have been carried out on SS-410 and En-31 steel. Their physical properties and compositions are given in Table -1 and 2 respectively.

Table-1: Physical properties of the base material

\begin{tabular}{|l|l|l|l|l|l|}
\hline Material & Density $\left(\mathrm{kg} / \mathrm{m}^{3}\right)$ & Melting Point $\left({ }^{\circ} \mathrm{C}\right)$ & $\begin{array}{l}\text { Thermal Conductivity } \\
\left(W \cdot \mathrm{m}^{-1} \cdot \mathrm{K}^{-1}\right)\end{array}$ & $\begin{array}{l}\text { Sp.heat }(\mathrm{Cp}) \\
(\mathrm{J} / \mathrm{kg} \mathrm{K})\end{array}$ & $\begin{array}{l}\text { Vickers Hardness } \\
(\mathrm{HV})\end{array}$ \\
\hline SS-410 & 7700 & 1530 & 28.7 & .029 & $160 \pm 4$ \\
\hline EN-31 Steel & 7810 & 1200 & 46.6 & 0.0452 & $180 \pm 6$ \\
\hline
\end{tabular}

Table-2: Chemical composition of base material

\begin{tabular}{|l|l|l|l|l|l|l|l|}
\hline Material & $\mathrm{C}$ & $\mathrm{Mn}$ & $\mathrm{Si}$ & $\mathrm{S}$ & $\mathrm{P}$ & $\mathrm{Cr}$ & $\mathrm{Fe}$ \\
\hline SS-410 & 0.14 & 1.06 & 0.38 & 0.019 & 0.022 & 15.70 & Remainder \\
\hline EN31 Steel & 0.92 & 0.58 & 0.30 & 0.024 & 0.020 & 1.48 & Remainder \\
\hline
\end{tabular}

Surface fusion was carried out using TIG pulse arc generated from a 'Fronius' Magicwave 1700 pulsed TIG welding Machine. Arc was generated in DCEN mode between work piece and the non consumable thoriated tungsten electrode of $3.2 \mathrm{~mm}$ diameter Commercial argon gas with flow rate of $18 \mathrm{~L} / \mathrm{min}$ was used to provide inert atmosphere. The size of BM used in this work was $150 \times 75 \times 5 \mathrm{~mm}$. prior cleaning of surfaces were done by 
rubbing with the emery paper followed by wiping with acetone in order to make it free from contaminations such as rust and grease.

Pulse frequencies (f) of 2, 4 and $6 \mathrm{~Hz}$ for SS-410 and $0.5,1,2$ and $4 \mathrm{~Hz}$ for En-31 were selected based on an earlier work reported [i] in this area and the thermal pulsing frequency suggested in [iii].

The arcing was carried on SS-410 at a heat input of $7.28 \pm 0.24 \mathrm{~kJ} / \mathrm{cm}$ estimated by $[(\eta \times \mathrm{AxV}) / \mathrm{S}]$ where, the system efficiency $\eta$ has been considered as 0.75 [3]. Keeping mean current $\left(\mathrm{I}_{\mathrm{m}}\right)$ constant at $132.5 \pm 4.5$ A the different peak and base current used are shown in Table-3.

Arcing was carried out on En-31 at a given heat input of $7.04 \pm 0.94 \mathrm{~kJ} / \mathrm{cm}$ estimated by $[(\eta \times A x V) / S]$ where, the system efficiency $\eta$ has been considered as 0.75 [iv]. The PTIGA was carried with parameters as noted in Table -4

In both cases arc voltage (V) and torch travel speed (S) was kept practically constant as $11 \mathrm{~V}, 9 \mathrm{~cm} / \mathrm{min}$. Duty cycle was kept at $50 \%$ for SS-410 and duty cycle was varied from $30 \%$ to $70 \%$ for En-31. During experimental work the voltage fluctuation noted was less than $\pm 10 \%$ while current fluctuation was less than $\pm 0.25 \%$. Fusion was carried out by single pass arcing procedure as typically shown (Fig.1).

The surface characteristics of each modified sample were studied on the samples machined out from a distance more than $12 \mathrm{~mm}$ from the arc initiation point along the arc travel line in order to ensure the stable temperature zone of fusion. To measure the depth of fusion the specimens were prepared by standard metallographic procedure of polishing with emery papers of different grit sizes followed by final polishing with diamond paste and subsequent electrolytic etching in aqueous solution of $10 \%$ acetic acid for SS-410 and $2 \%$ Nital etching for En-31. Vickers pyramid hardness (HV) was measured on the polished surface transverse to arc travel line by indentation at $10 \mathrm{kgf}$ force with $15 \mathrm{sec}$ dwell time.

Table-3: TIG Pulse arcing parameters used

\begin{tabular}{|c|c|c|c|c|c|c|}
\hline \multirow{2}{*}{$\begin{array}{l}\text { Sl. } \\
\text { N } \\
\text { o. }\end{array}$} & \multicolumn{6}{|c|}{ Pulse arcing parameters } \\
\hline & $\begin{array}{l}\mathrm{I}_{\mathrm{P}} \\
(\mathrm{A})\end{array}$ & $\begin{array}{l}\mathrm{I}_{\mathrm{b}} \\
(\mathrm{A})\end{array}$ & $\begin{array}{l}\mathrm{I}_{\mathrm{m}} \\
(\mathrm{A})^{*}\end{array}$ & $\begin{array}{l}\mathrm{f} \\
(\mathrm{Hz})\end{array}$ & $\begin{array}{l}\mathrm{t}_{\mathrm{p}}=\mathrm{t}_{\mathrm{b}} \\
(\mathrm{ms})\end{array}$ & $\phi$ \\
\hline \multirow{3}{*}{1} & \multirow{3}{*}{170} & \multirow{3}{*}{86} & \multirow{3}{*}{128} & 2 & 250 & \multirow{3}{*}{0.25} \\
\hline & & & & 4 & 125 & \\
\hline & & & & 6 & 83 & \\
\hline \multirow{3}{*}{2} & \multirow{3}{*}{164} & \multirow{3}{*}{98} & \multirow{3}{*}{131} & 2 & 250 & \multirow{3}{*}{0.30} \\
\hline & & & & 4 & 125 & \\
\hline & & & & 6 & 83 & \\
\hline \multirow{3}{*}{3} & \multirow{3}{*}{158} & \multirow{3}{*}{110} & \multirow{3}{*}{134} & 2 & 250 & \multirow[t]{3}{*}{0.35} \\
\hline & & & & 4 & 125 & \\
\hline & & & & 6 & 83 & \\
\hline \multirow{3}{*}{4} & \multirow{3}{*}{152} & \multirow{3}{*}{122} & \multirow{3}{*}{137} & 2 & 250 & \multirow[t]{3}{*}{0.40} \\
\hline & & & & 4 & 125 & \\
\hline & & & & 6 & 83 & \\
\hline
\end{tabular}

Table-4: Pulse current TIG arcing parameters for En-31

\begin{tabular}{|c|c|c|c|c|c|c|c|}
\hline $\begin{array}{l}\mathrm{I}_{\mathrm{P}} \\
(\mathrm{A})\end{array}$ & $\begin{array}{l}\mathrm{I}_{\mathrm{b}} \\
(\mathrm{A})\end{array}$ & $\begin{array}{l}\text { f } \\
(\mathrm{Hz})\end{array}$ & $\begin{array}{l}\text { Duty } \\
\text { cycle } \\
(\%)\end{array}$ & $\mathrm{t}_{\mathrm{p}}(\mathrm{ms})$ & $\begin{array}{l}\mathrm{t}_{\mathrm{b}} \\
(\mathrm{ms})\end{array}$ & $\begin{array}{l}* \mathrm{I}_{\mathrm{m}} \\
\text { (A) }\end{array}$ & $\phi$ \\
\hline \multirow{12}{*}{170} & \multirow{12}{*}{86} & \multirow[t]{3}{*}{0.5} & 30 & 600 & 1400 & 111 & 0.35 \\
\hline & & & 50 & 1000 & 1000 & 128 & 0.25 \\
\hline & & & 70 & 1400 & 600 & 145 & 0.15 \\
\hline & & \multirow[t]{3}{*}{1.0} & 30 & 300 & 700 & 111 & 0.35 \\
\hline & & & 50 & 500 & 500 & 128 & 0.25 \\
\hline & & & 70 & 700 & 300 & 145 & 0.15 \\
\hline & & \multirow[t]{3}{*}{2} & 30 & 150 & 350 & 111 & 0.35 \\
\hline & & & 50 & 250 & 250 & 128 & 0.25 \\
\hline & & & 70 & 350 & 150 & 145 & 0.15 \\
\hline & & \multirow[t]{3}{*}{4} & 30 & 75 & 175 & 111 & 0.35 \\
\hline & & & 50 & 125 & 125 & 128 & 0.25 \\
\hline & & & 70 & 175 & 75 & 145 & 0.15 \\
\hline
\end{tabular}

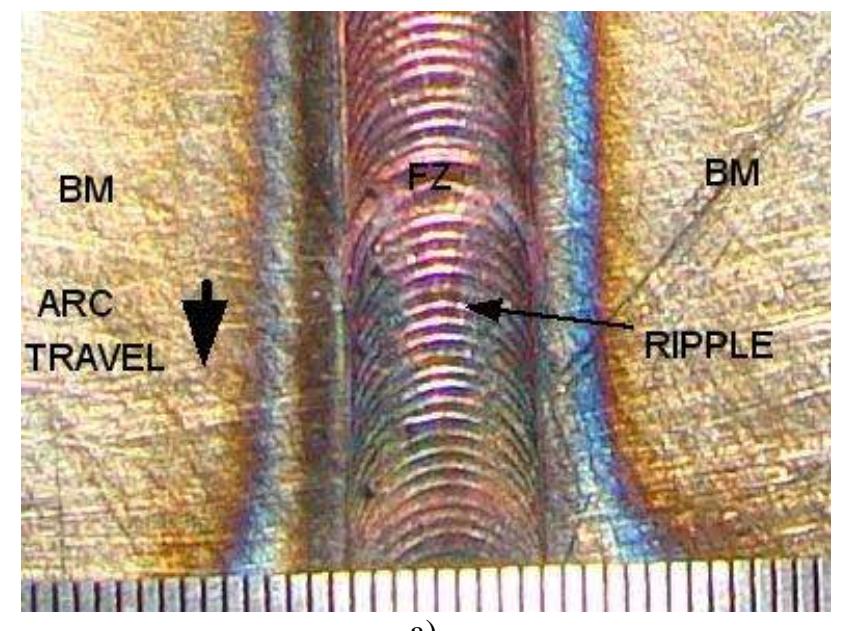

a)

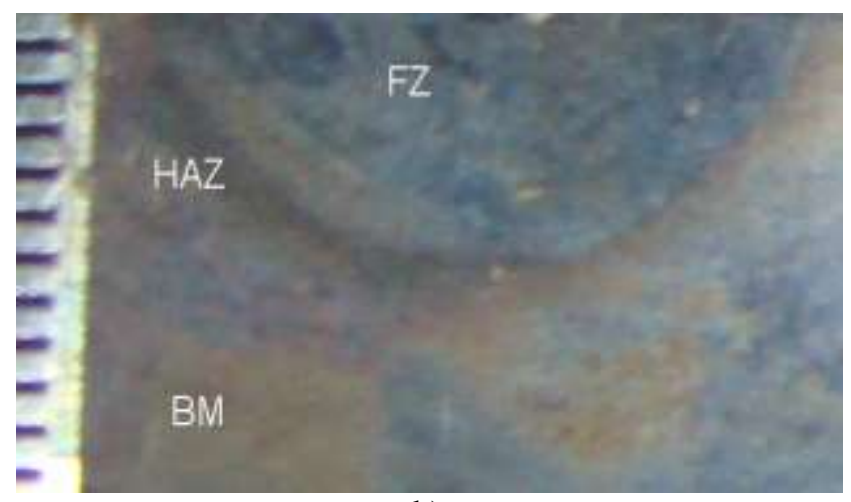

b)

Fig.1: Typical surface zones at single pass arcing a) along b) across arc travel surface

\section{RESULTS AND DISCUSSIONS}

\subsection{Surface Appearance of Fused Zone}

Surface appearance of FZ was thoroughly studied with respect to ripple formations representing the solidification behavior at different $f$ and $\phi$ values. 
Some typical photographs of the ripple formation for SS410 (Fig.2) and En-31 (Fig.3) are shown. For SS-410 ripples are uniform and stable having different widths, curvatures and no/unit length depending on $\mathrm{f}$ and $\phi$. In En-31steel fusion is erratic and irregular ripple patterns are generated.

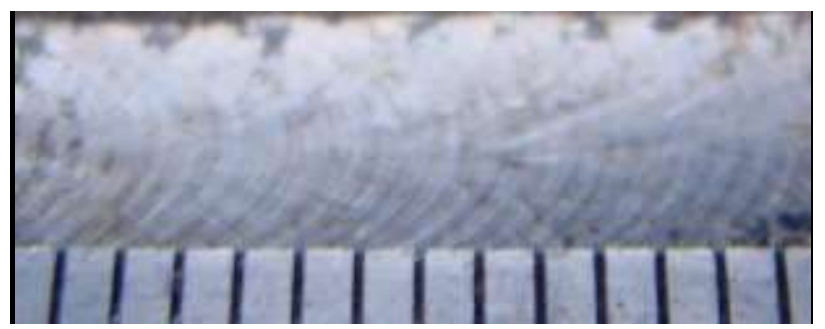

a)

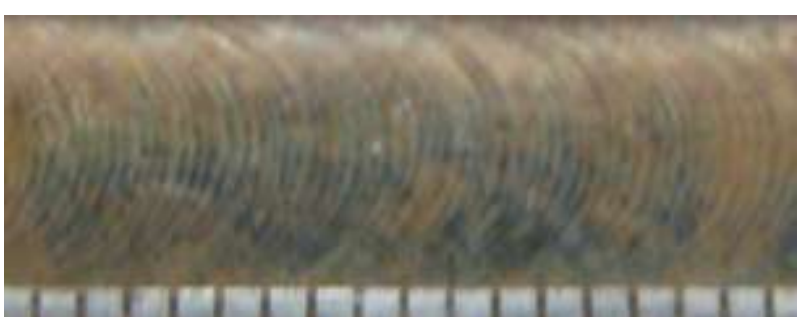

b)

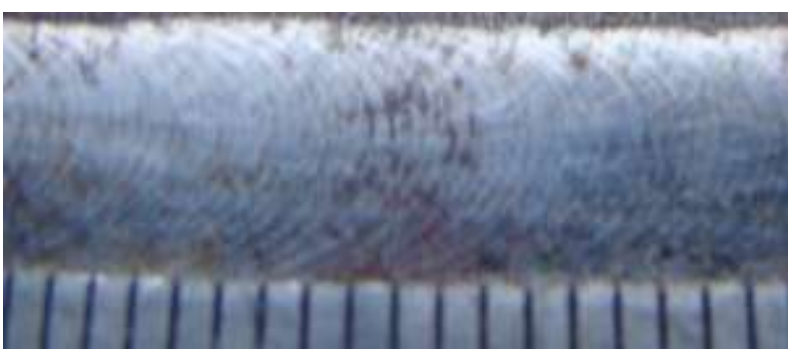

c)

Fig.2: Typical ripple formation on fused surface of SS-410 at a) $2 \mathrm{~Hz}, \phi=0.35 \mathrm{~b}) 4 \mathrm{~Hz}, \phi=0.4$ c) $6 \mathrm{~Hz}, \phi=0.25$ with heat input $7.28 \mathrm{~kJ} / \mathrm{cm}$. Scale: $\mathrm{mm}$

It appears that $\mathrm{f}$ and $\phi$ have appreciable effect on number of ripples/cm which indicates the coarsening of ripple that in turn broadly indicates the cooling characteristics of the FZ. At various $f$ the effect of $\phi$ on ripple concentration per unit length of FZ has been shown in Fig. 4 a) and b). The figures shows that at a given $\phi$ the increase off as well as at a given $f$ the increase of $\phi$ significantly enhances the number of ripples per unit length by making it appreciably finer.

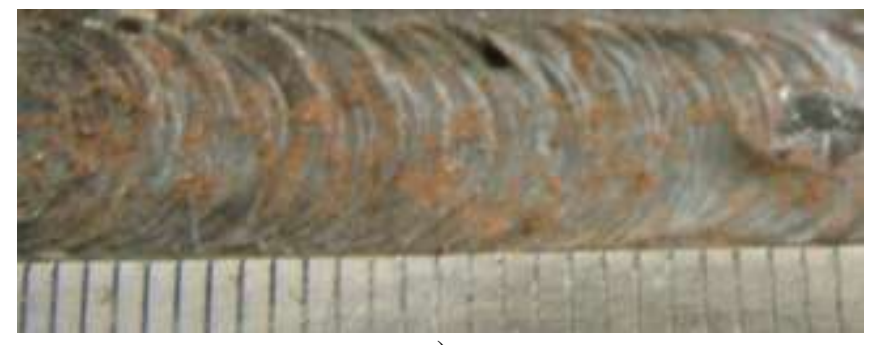

a)

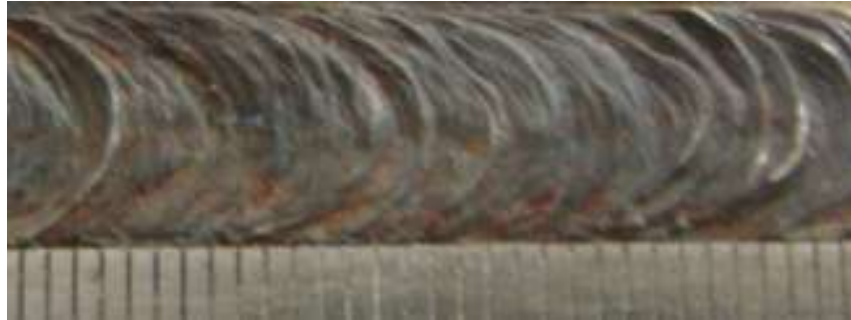

b)

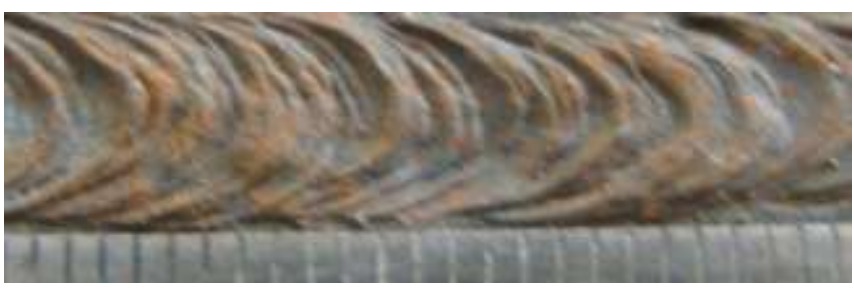

c)

Fig.3: Typical ripple formation on solidified surface of En31 at (a) $0.5 \mathrm{~Hz} \phi=.0 .25$ (b) $1 \mathrm{~Hz} \phi=0.25$ (c) $2 \mathrm{~Hz} \phi=0.35$ and a given heat input $7.04 \mathrm{~kJ} / \mathrm{cm}$. Scale: in $\mathrm{mm}$

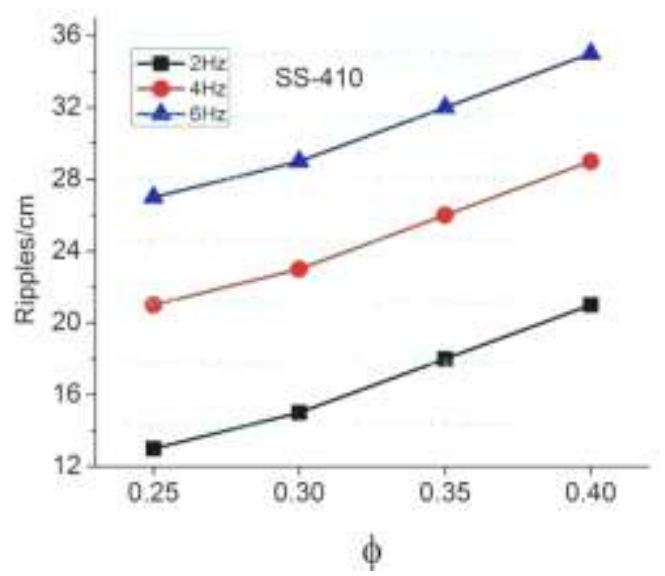

a)

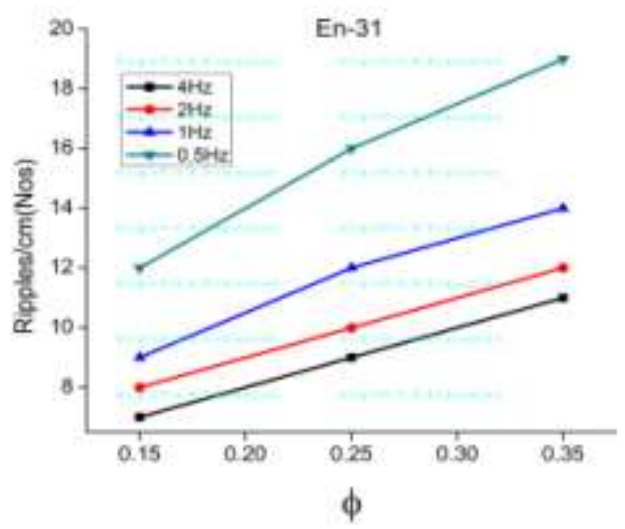

b)

Fig.4: Effect of pulse frequency and $\phi$ on ripple concentration per unit length of fused surface of a) SS-410 with heat input $7.28 \mathrm{~kJ} / \mathrm{cm}$ and b) En-31 with heat input 7.04 $\mathrm{kJ} / \mathrm{cm}$. 


\subsection{Geometry of Fused Zone}

\subsubsection{Width of Fusion Zone}

\subsubsection{For SS-410}

At a given heat input of $7.28 \mathrm{~kJ} / \mathrm{cm}$ the effect of $\phi$ on the measured width of the FZ of SS-410 is shown in(Fig. 5a)The measured $\mathrm{FZ}$ width lies between $5.6 \mathrm{~mm}$ (at $\mathrm{f}=6 \mathrm{~Hz}$ and $\phi=0.4$ ) to $7.5 \mathrm{~mm}$ ( at $\mathrm{f}=2 \mathrm{~Hz}$ and $\phi=0.3$.) A relative lowering of FZ width with decrease of $\phi$ from 0.3 to 0.25 may have happened due to some predominant compromising effect of $\phi$ in reduction of heat built up in fusion over the effect of $f$ on enhancement of the same up to certain extent.

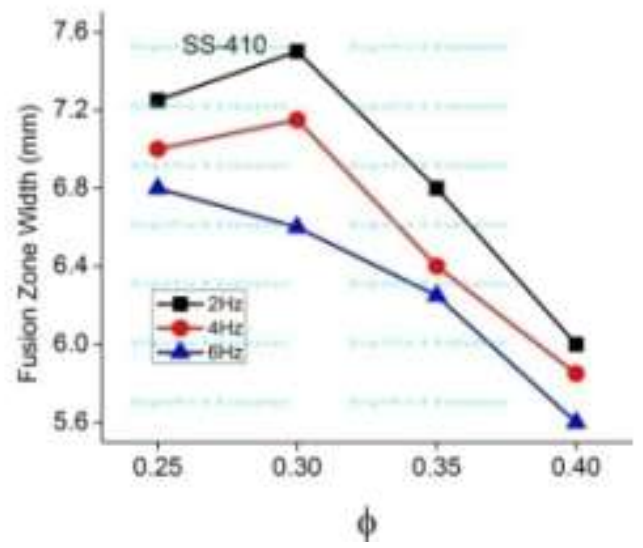

a)

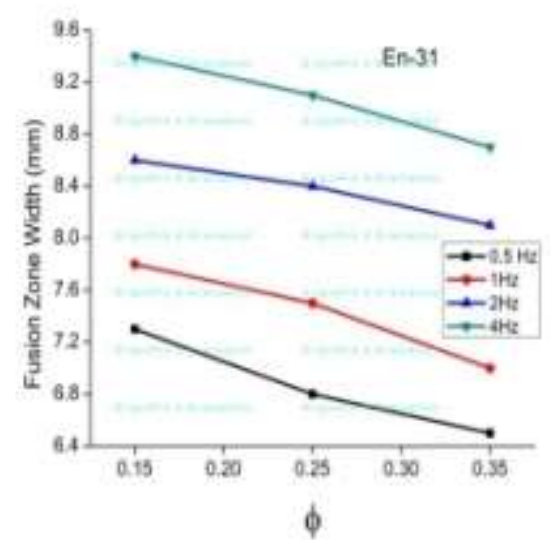

b)

Fig.5: The effect of $\phi$ on measured FZ width at different $f$ in a) SS-410 with heat input $7.28 \pm 0.24 \mathrm{~kJ} / \mathrm{cm}$ and b)En-31 with heat input $7.04 \mathrm{~kJ} / \mathrm{cm}$...

\subsubsection{For En-31}

At a given heat input of $7.04 \mathrm{~kJ} / \mathrm{cm}$ the effect of $\phi$ on the width of FZ as observed at different $\mathrm{f}$ is shown in (Fig. 5.b). The figure shows that in general at a given heat input the increase of $\phi$ at a given $f$ and the increase of $f$ at a given $\phi$ significantly reduces the width of the FZ.The minimum fusion width as $6.5 \mathrm{~mm}$ is found at $\mathrm{f}=0.5 \mathrm{~Hz}$ and $\phi=0.35$ while its maximum value of $9.4 \mathrm{~mm}$ is noted at $\mathrm{f}=4 \mathrm{~Hz}$ and $=0.15$.

\subsubsection{Depth of Fusion}

\subsubsection{SS-410}

Some typical photographs of FZ depth are shown in Fig.6.The measured values are plotted in Fig.7a).It is observed that though heat input remained unchanged, still with increase of $\phi$ at a given $\mathrm{f}$ and increase of $\mathrm{f}$ at a given $\phi$ reduces the depth of $\mathrm{FZ}$ in the SS-410 BM.The maximum depth of $2.1 \mathrm{~mm}$ was found at $\mathrm{f}=2 \mathrm{~Hz}$ and $\phi=0.25$ while the minimum of $1.75 \mathrm{~mm}$ was found at $\mathrm{f}=6 \mathrm{~Hz}$ and $\phi=0.4$

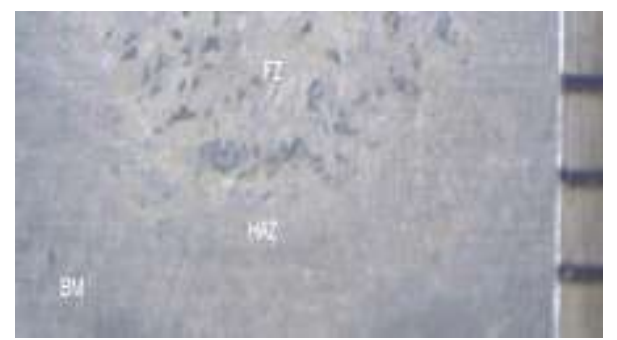

a)

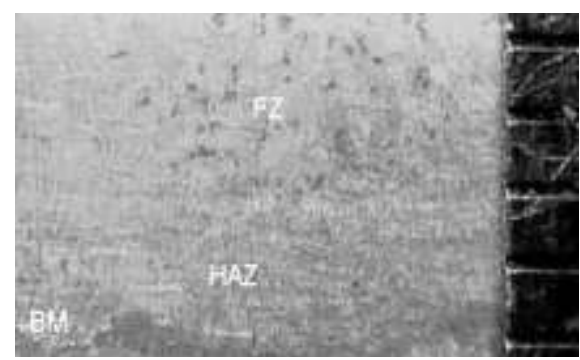

b)

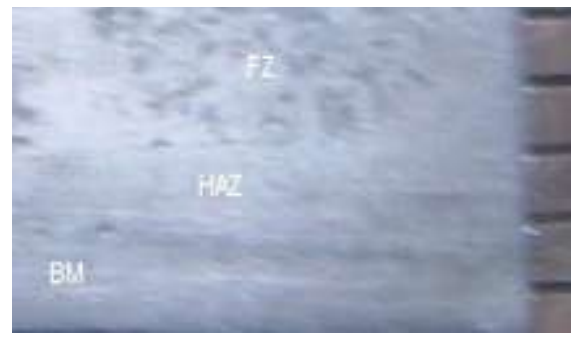

c)

Fig.6: Typical fused zone across arc travel surface of SS410 at (a) $2 \mathrm{~Hz}, \phi=0.25$ (b) $6 \mathrm{~Hz}, \phi=0.25$ (c) $6 \mathrm{~Hz}, \phi=0.35$. Scale: in $\mathrm{mm}$.

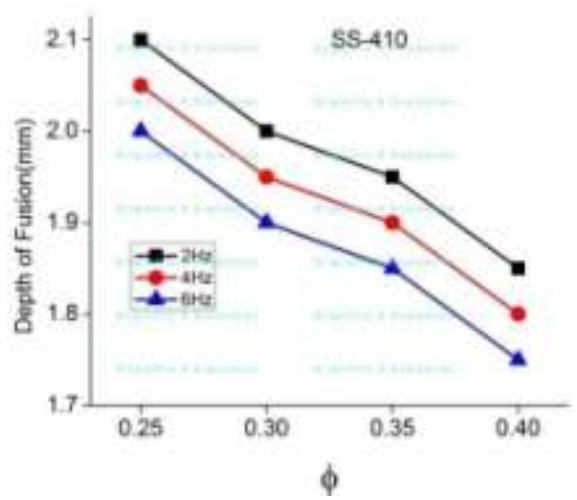

a) 


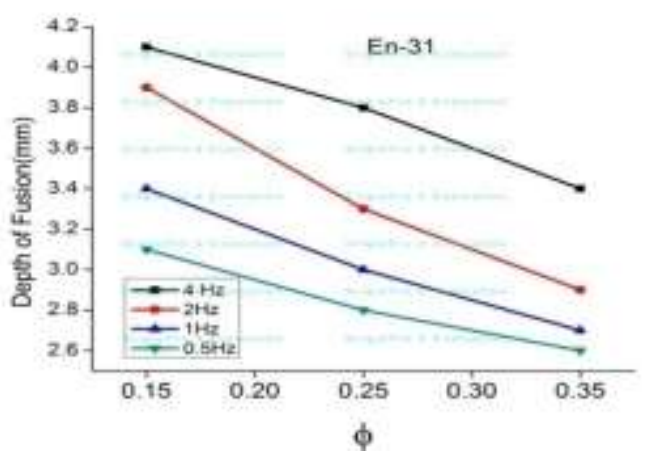

b)

Fig. 7: The effect of $\phi$ on measured depth of FZ at different $\mathrm{f}$ in a) SS-410 with heat input $7.28 \mathrm{~kJ} / \mathrm{cm}$ b) En-31 with heat input $7.04 \mathrm{~kJ} / \mathrm{cm}$.

\subsubsection{En-31}

Some typical photographs of FZ depth are shown in Fig.8.The measured depth of fusion as a function of the $\phi$ and $\mathrm{f}$ has been shown in Fig.7b) and found to be maximum of $4.1 \mathrm{~mm}$ at $\mathrm{f}=4 \mathrm{~Hz}$ and $\phi=0.15$ while minimum of 2.6 $\mathrm{mm}$ at $\mathrm{f}=0.5 \mathrm{~Hz}$ and $\phi=0.35$.

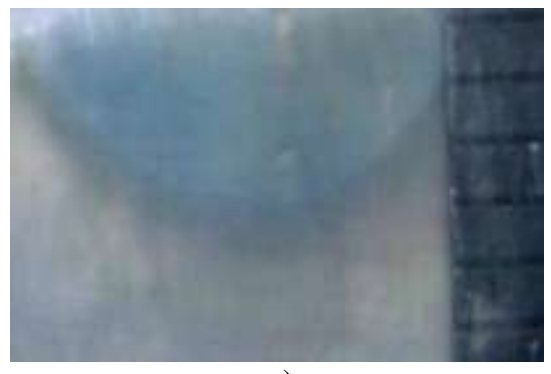

a)

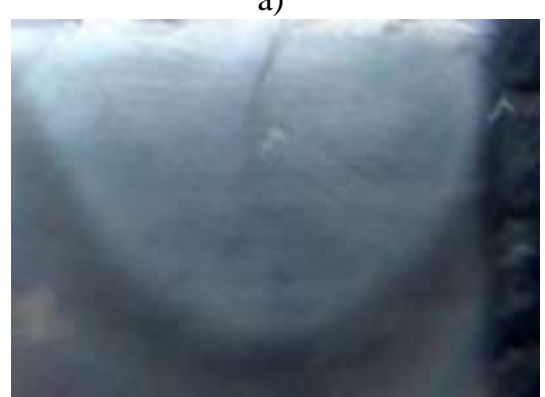

b)

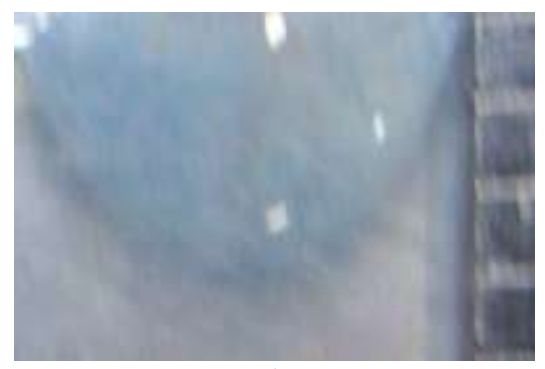

c)

Fig. 8: Typical fused zone across arc travel surface of En-31 at (a) $0.5 \mathrm{~Hz}, \phi=0.15$ (b) $0.5 \mathrm{~Hz}, \phi=0.35$ (c) $1 \mathrm{~Hz}, \phi=0.25$. Scale: in $\mathrm{mm}$.
So it can be seen that $\mathrm{f}$ and $\phi$ has considerable effect on FZ size.

\subsection{Cooling Rate}

The surface appearance of $\mathrm{FZ}$ with respect to ripple formation at different parameters of TIGPA process has been used to estimate the cooling rate of the fused zone in the line of a successful analysis reported earlier [v, vi, vii]. The geometric approach of the analysis of ripple characteristics has been schematically shown in Fig. 9. The analytical expressions used for estimation of cooling rate are shown in equations (2) to (6).

$$
\begin{aligned}
& \text { Ripple lag ratio }\left(\mathrm{R}_{\mathrm{lg}}\right)=\mathrm{L}_{\mathrm{rg}} / \mathrm{W}_{\mathrm{rg}} \\
& \text { Growth Rate }\left(\mathrm{R}_{\mathrm{G}}\right)=\mathrm{S} \cos \boldsymbol{\alpha}
\end{aligned}
$$

Solidification temperature gradient $(\mathrm{G})=\mathrm{T}_{\mathrm{m}} / \mathrm{X}_{\mathrm{hw}}-\cdots$

$$
\begin{aligned}
& \text { Cooling Rate }\left(\mathrm{C}_{\mathrm{R}}\right)=\mathrm{GR}_{\mathrm{G}} \boldsymbol{\theta} \\
& \boldsymbol{\theta}=\tan ^{-1}\left(\mathrm{~W}_{\mathrm{rg}} / 2 \mathrm{~L}_{\mathrm{rg}}\right)
\end{aligned}
$$

where, $\mathrm{L}_{\mathrm{rg}}$ is length of ripple lag, $\mathrm{W}_{\mathrm{rg}}$ is width of molten pool, $\mathrm{T}_{\mathrm{m}}$ ismelting temperature of base plate and $\mathrm{X}_{\mathrm{hw}}$ is distance between heat source and rear of the weld pool. All quantitative measurements on the fused surfaces were performed with Adobe Photoshop 7 applied on fused zone photographs captured in computer.

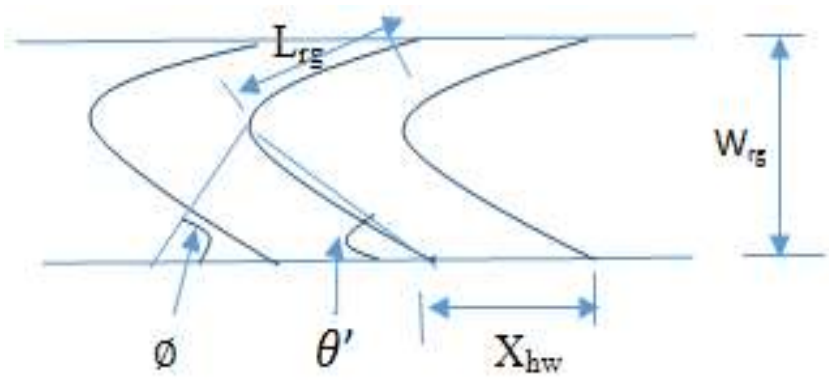

Fig. 9: Schematic diagram showing the characteristic features of ripples on fused surface.

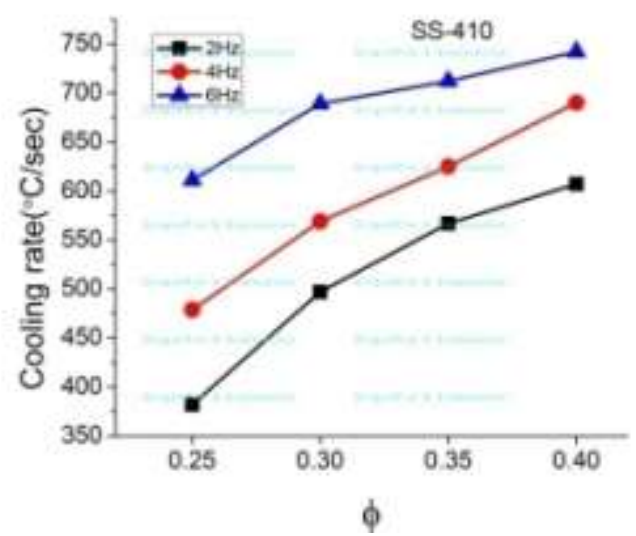

a) 


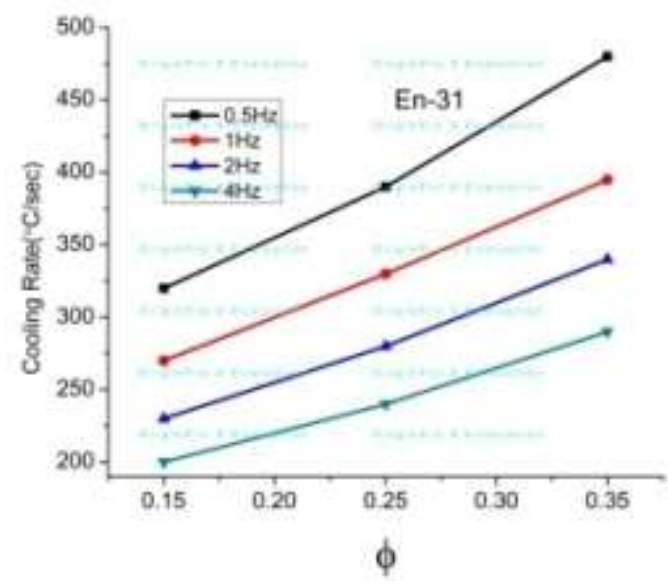

b)

Fig. 10: Effect of pulse frequency and $\phi$ on estimated cooling rate of FZ in a) SS-410 with heat input $7.28 \mathrm{~kJ} / \mathrm{cm}$ b) En-31 with heat input $7.04 \mathrm{~kJ} / \mathrm{cm}$.

\subsubsection{SS-410}

From Fig.10a) it can be seen that the cooling rate at $2 \mathrm{~Hz}$ varied from $382{ }^{\circ} \mathrm{C} / \mathrm{s}$ at $\phi=0.25$ to $605{ }^{\circ} \mathrm{C} / \mathrm{s}$ at $\phi=0.4$, whereas the corresponding values at $6 \mathrm{~Hz}$ are $611{ }^{\circ} \mathrm{C} / \mathrm{s}$ and $740^{\circ} \mathrm{C} / \mathrm{s}$ respectively.

\subsubsection{En-31}

From Fig.10b) the cooling rate at $0.5 \mathrm{~Hz}$ varies from 315 ${ }^{\circ} \mathrm{C} / \mathrm{sec}$ at $\phi=0.25$ to $485{ }^{\circ} \mathrm{C} / \mathrm{sec}$.at $\phi=0.4$ whereas the corresponding values at $4 \mathrm{~Hz}$ are $207^{\circ} \mathrm{C} / \mathrm{sec}$ and $289^{\circ} \mathrm{C} / \mathrm{sec}$ respectively.

\subsection{Hardness}

\subsubsection{SS-410}

The nature of variation of average hardness of surface across arc travel direction of the FZ and HAZ adjacent to the FZ as a function of $\phi$ at different pulse frequencies has been shown in Fig. 11(a- c). Hardness of modified matrix has been found relatively higher than that of the BM found as $160 \pm 4 \mathrm{HV}$ (Table 1). From the figures it appears that at any pulse frequency the increase of $\phi$ from 0.25 to 0.4 significantly improves the hardness of both the FZ and HAZ. It is also found that at a given $\phi$ the increase of pulse frequency generally reduces the hardness of $\mathrm{FZ}$ as well as HAZ. The maximum average hardness $(210 \mathrm{HV})$ of FZ has been found at $\phi=0.4$ and pulse frequency of $2 \mathrm{~Hz}$ which is about $30 \%$ higher than that of the BM. Similarly the hardness of HAZ has been found to be raised up to about $231 \mathrm{HV}$ which is also about $43 \%$ higher than that of the BM.

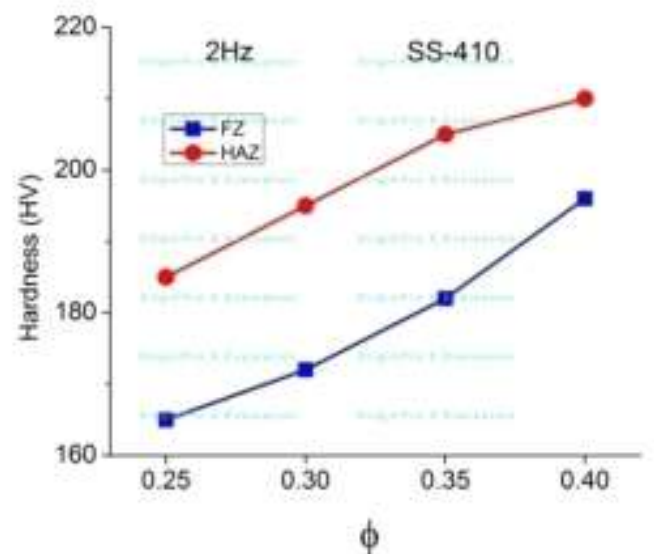

a)

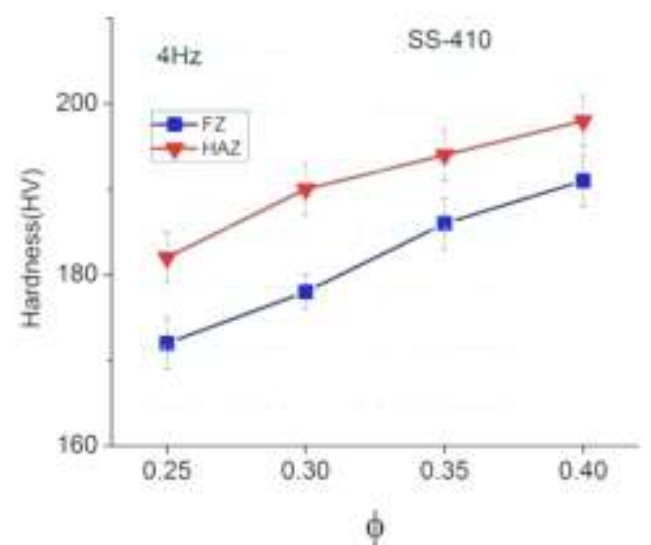

b)

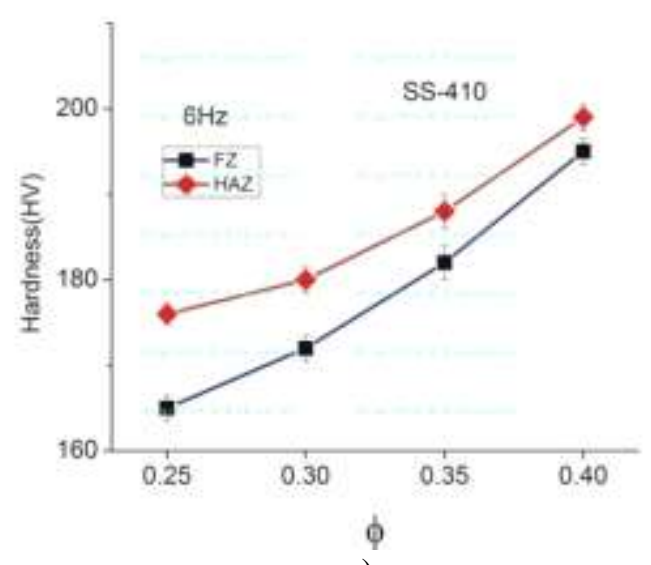

c)

Fig.11:.Effect of $\phi$ on hardness of FZ and HAZ at different pulse frequencies a) $2 \mathrm{Hzb}$ ) $4 \mathrm{Hzand} \mathrm{c)} 6 \mathrm{~Hz}$

\subsubsection{En-31}

The nature of variation of average hardness of the surface across arc travel direction of the FZ and the HAZ of BM adjacent to the $F Z$ as a function of $\phi$ at different $f$ have been shown in Figs.12 (a-d).The maximum rise of average hardness of FZ has been found of the order of $415 \mathrm{HV}$ 
during arcing at the $\phi=0.35$ and $\mathrm{f}=4 \mathrm{~Hz}$ which is about $130 \%$ higher than that of the BM found as $180 \pm 6$ HVTable 1). Similarly the hardness of HAZ at same parameter has been found to be raised up to about $292 \mathrm{HV}$ which is also about $62 \%$ higher than that of the BM.

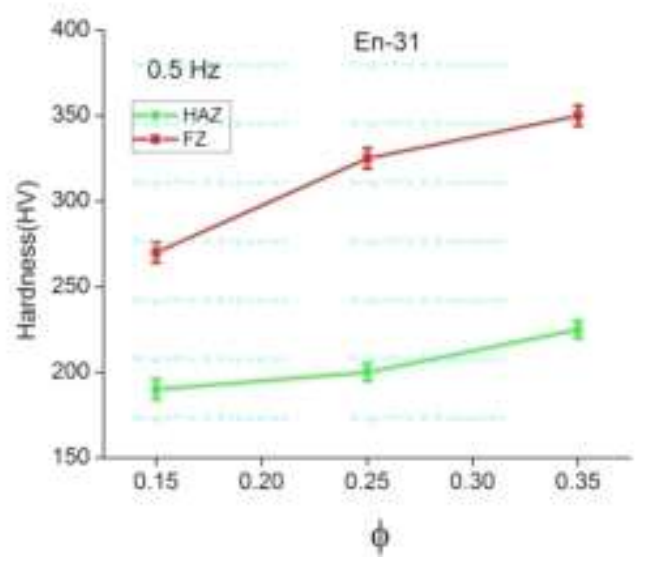

a)

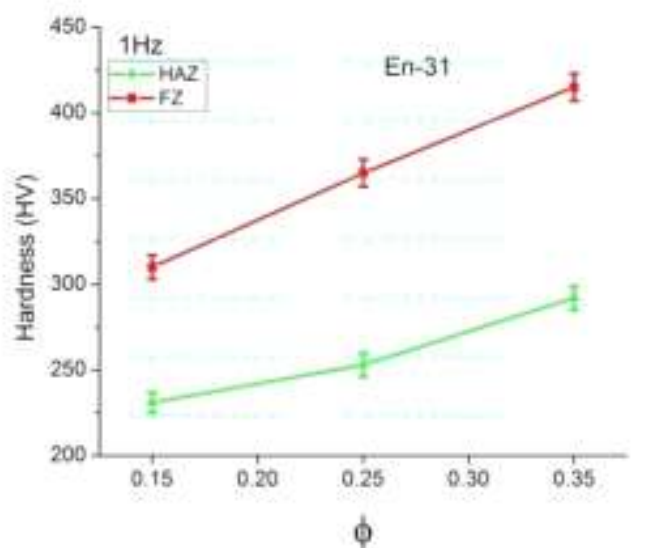

b)

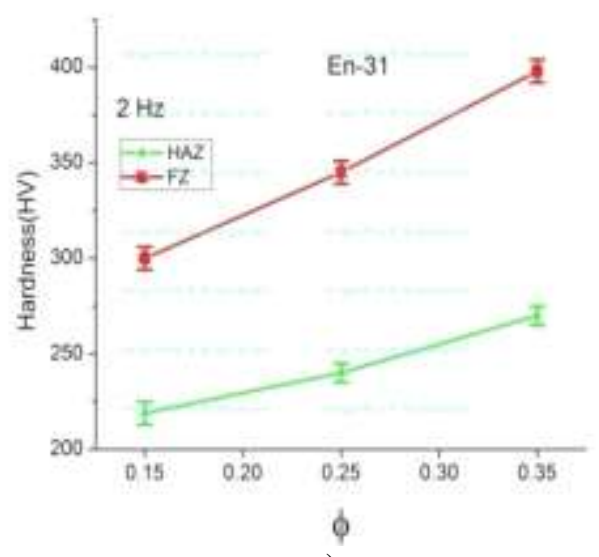

c)

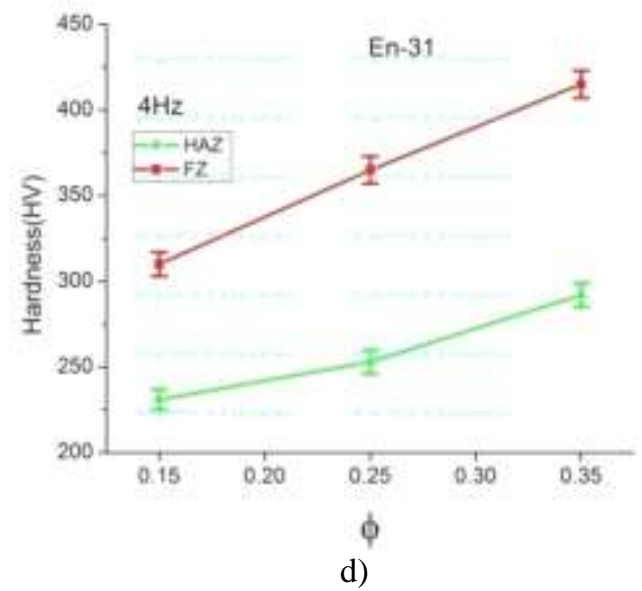

Fig.12: Effect of $\phi$ on hardness of $\mathrm{FZ}$ and HAZ at different pulse frequencies a) $0.5 \mathrm{Hzb}$ ) $1 \mathrm{Hzc}) 2 \mathrm{~Hz}$ and d) $4 \mathrm{~Hz}$.

\section{CONCLUSION}

So from experimental work and subsequent analysis following conclusions are drawn

a) At a particular heat input with use of pulsing, fusion zone shape in Steel can be changed

b) With use of a dimensionless parameter Tungsten Inert Gas pulsed arcing process can be effectively controlled

c) Cooling rate can be theoretically calculated

d) Hardness of the material can be appreciably modified

e) This method can be further studied for application in surface property modification.

\section{REFERENCES}

[1] Ghosh, P.K., Goyal, V.K., Dhiman, H.K. and Kumar,M.(2006)," Thermal and metal transfer behavior in pulsed current gas metal arc weld deposition of Al-Mg alloy", Sci \& technol of welding and joining,Science and technology of welding and Joining,Vol.11,Issue2,pp232-242.

[2] 2Ghosh,P.K.and Kumar,R.(2014) "Surface modification of Micro-Alloyed high-strength low-alloy steel by controlled TIG arcing process", The Minerals,Metals\& Materials Society and ASMInternational,doi:10.1007/s11661-014-2670-x@,.

[3] Fronius international, $\mathrm{GmbH}$, Magic wave machine manual

[4] K.Poorhaydari, B.M.Patchett, D.G.Ivey, (2005)" Estimation of cooling rate in the welding of plates with intermediate thickness", WeldingResearch, October, pp149-s-155-s

[5] Christensen, N., de L. Davis, V. Gjermundsen, K., [1965] "Distribution of temperature in arc welding", British Welding Journal. Vol.12 (2), pp. 54-75

[6] Robert W. Messler, Jr., [1999] "Principles of Welding" John Wiley and sons, New York.

[7] Radaij, D., [1992], "Heat effects on welding", Springer-Verlag, USA. 